\title{
"O SERTÃO É O MUNDO" E O "PRINCÍPIO GERAL DE REVERSIBILIDADE": DOIS CONCEITOS FUNDADORES DA CRIITICA ROSIANA
}

\author{
Claudio Cuccagna (USP)
}

\section{I}

A bibliografia crítica sobre a obra de Guimarães Rosa é uma das mais vastas do panorama literário brasileiro. Atualmente ela não tende a minguar o ritmo de suas produções, nem a preocupação pela procura de novas chaves interpretativas e de novas abordagens de estudo, capazes de obviar àquela inevitável e entrópica dispersão de compreensão, que sempre ocorre durante o processo perceptivo de uma obra rica e complexa, como costuma ser a rosiana.

Embora só aparentemente pareça ter-se esgotado a veia dos principais argumentos de investigação, cada qual dos estudos críticos levantados é sempre capaz de acrescentar ao grande caudal das teorizações interpretativas um elemento novo, útil para o desvendamento e a enucleação do "grosso misturado" que caracteriza a obra do escritor mineiro. Dentro desse processo interpretativo - que da obra leva em conta ora os aspectos gerais, ora os específicos, ora os dois juntamente -, enquanto alguns estudos tentam sondar âmbitos rosianos ainda pouco conhecidos, outros se preocupam, além disso, em desenvolver conceitos e sugestões semeados pelos pioneiros dessa tradição crítica. É o que se passa, por exemplo, em relação a dois conceitos interpretativos elaborados por Antonio Candido, a saber, "O Sertão é o Mundo" e o chamado "princípio geral de reversibilidade", ambos formulados a partir da análise da obra-prima Grande sertão: veredas.

Verdadeiros conceitos fundadores de um modo de focalizar e captar a obra rosiana, a grande consagração crítica que eles receberam não só é devida a uma lógica consideração cronológica - pois, de fato. eles se põem, junto a outros, à origem dessa trajetória crítica -, mas também a uma objetiva capacidade de síntese interpretativa da matéria rosiana, hábil em detectar, desde logo, os princípios básicos de 
funcionalidade e de alcance significativo que a regem. Caracteristicas que fizeram com que os mencionados conceitos candidianos, a partir de sua primeira aparição no ensaio "O sertão e o mundo" (1957. O título foi sucessivamente transformado em "O homem dos avessos", 1964), se tornassem pontos inamovíveis e sempre atuais dos posteriores estudos e debates críticos elaborados sobre a obra rosiana e, de maneira especifica, retomando as palavras do Alfredo Bosi da História concisa. sobre essa "obra espantosa que é Grande Sertão: Veredas".

\section{"O Sertão é o Mundo"}

O primeiro dos dois conceitos em questão, que iremos separadamente analisar - ainda que, na verdade, os dois permaneçam intimamente ligados entre si -, é o relativo a "O Sertão é o Mundo". $\mathrm{Na}$ particular forma de Guimarães Rosa tratar a terra e os homens do sertão mineiro, Antonio Candido divisava uma atitude voltada à deformação da realidade empirica para fins que a transcendiam. E o começo desse processo de transformação residia na consciência que Guimarães Rosa tinha a respeito das grandes potencialidades artísticas imanentes a esta matéria sertaneja que, por isso mesmo, ter-se-ia prestado a fascinantes metamorfoses:

Para o artista, o mundo e o homem são abismos de virtualidades, e ele será tanto mais original quanto mais fundo baixar na pesquisa, trazendo como resultado um mundo e um homem diferentes, compostos de elementos que deformou a partir dos modelos reais, consciente ou inconscientemente propostos. ${ }^{1}$

A primeira fase deste processo transformacional, que levará o Sertão a significar o Mundo, está, pois, na alteração e manuseio artístico de dados e observações colhidos da realidade. É, com efeito. graças a este processo criativo, à sábia invenção, que. segundo Antonio Candido,

tudo [em Grande sertão: veredas] se transformou em significado universal [...], que subtrai o livro à matriz regional para fazê-lo exprimir os grandes lugares-comuns, sem os quais a arte não sobrevive: dor, júbilo, ódio, amor, morte, - para cuja órbita nos arrasta a cada instante.

Antonio Candido, O homem dos avessos. In: Eduardo F. Coutinho (org.).

Guimarães Rosa. 1991, p. 294-95. 
mostrando que o pitoresco é acessório e que na verdade o Sertão é o Mundo. ${ }^{2}$

Portanto, é através da invenção artística que Guimarães Rosa pôde plasmar e transformar o plano da realidade geográficoantropológica do sertão de Minas em algo de novo; algo que filtrado pela sua erudição pessoal, pudesse representar não mais, ou não apenas, o mundo sertanejo mineiro stricto sensu, mas dar vida ao "seu mundo, o seu homem, mais elucidativos que os da observação comum, porque feitos com as sementes que permitem chegar a uma realidade em potencia, mais ampla e mais significativa". 3

Este conceito de mundo rosiano, de criação de um universo ficcional diferente do da realidade observada, é, de resto, muito reiterado no ensaio candidiano. O substantivo universo e seu adjetivo universal, de fato, aparecem com freqüência em expressões tais como "universo autônomo", "expressão universal", "significado universal", "universo de Guimarães Rosa", "universo inventado", "universo fíctício". É sobretudo através do uso destas expressões que o crítico visa ressaltar a realização de uma dimensão artística rosiana, que vai além do simples contexto do homem e da terra do sertão mineiro, para atingir um plano semântico e expressivo de alcance universal.

Embora não explicitamente afirmado por Antonio Candido, a passagem da realidade sertaneja aos valores e significações universais presentes em Grande sertão: veredas, se dá graças a uma ação criadora e, por isso mesmo, mediadora do próprio escritor, este ciente de que, in nuce, "O Sertão é o Mundo" ou, dito com outra fórmula candidiana - que não muda a substância significativa do conceito, mas que, antes, mostra toda a imanência funcional dos dois termos -, da existência do "Sertão-enquanto-Mundo".

\section{$\mathrm{O}$ "princípio geral de reversibilidade"}

Mas qual é o mecanismo pelo qual se dá a efetivação desse conceito candidiano? Em outros termos: qual é o princípio que está por baixo dessa transformação do plano regional em plano universal vigente em Grande sertão: veredas? Depois de Antonio Candido ter detectado o caráter transcendente do regionalismo rosiano, ele passa a

Ibidem, p. 295.

Ibidem (grifo do autor). 
se ocupar da natureza dualística e ambigua presente em Grande sertão: veredas. Dualismo que permeia a terra e o homem da representação rosiana e que, em termos simbólicos, por exemplo, caracteriza a função de um dos protagonistas naturais do romance, o rio São Francisco: pois, este rio "[...] divide o mundo em duas partes qualitativamente diversas: o lado direito e o lado esquerdo, carregados do sentido mágico-simbólico que esta divisão representa para a mentalidade primitiva. O direito é o fasto; nefasto o esquerdo."

Todavia, este dualismo não se manifesta de forma rigidamente dada, e sim demonstra um certo grau de mobilidade. A ambivalência do mundo geográfico e humano, que presenciamos em Grande sertão: veredas, nunca é rígida e definitiva; ela está sempre em contínuo movimento, oscilando de um lado para outro e criando, assim, um caráter de coexistência entre os opostos. É o que Antonio Candido diz a respeito dos jagunços e, sobretudo, dentre estes, de Diadorim, personagem ambivalente por excelência do romance todo:

Simbolicamente, eles [os jagunços] vão e vêm de uma a outra margem [do rio São Francisco], cruzando e tocando as duas metades qualitativas do Sertão, do Mundo, pois Diadorim é uma experiência reversivel que une fasto e nefasto, licito e ilicito, sendo ele próprio duplo na sua condição.

Essa heterolateralidade [...] mostra a coexistência do real e do fantástico, amalgamados na invenção $e$, as mais das vezes, dificilmente separáveis. ${ }^{5}$

É de novo graças à ação criadora da invenção que é possível. no romance rosiano, a coincidentia oppositorum, a mistura, usando as palavras do próprio Candido há pouco citadas, "do real e do fantástico", e que, mutatis mutandis, nos faz pensar nas criações literárias do real maravilloso tão peculiares à literatura hispanoamericana. ${ }^{6}$ Mistura, ademais, que a invenção rosiana exerce por meio

\footnotetext{
Ibidem, p. 297.

Ibidem, p. 297-98.

Em um dos momentos conclusivos de "O homem dos avessos" (op. cit., p. 309), Antonio Candido, quase a querer confirmar a importância que reveste a invenção rosiana na mistura do plano real e fantástico presente em Grande sertão: veredas, assim se exprime: "Desliza [Riobaldo], então. entre o real e o fantástico, misturados na prodigiosa invenção de Guimarães Rosa como lei da narrativa. E nós podemos ver que o real é ininteligível sem o fantástico, e que ao mesmo tempo este é o caminho para o real."
} 
de uma reversibilidade dos opostos, que permeia todos os planos da obra.

As afirmações inerentes à mistura dos opostos a que chega Antonio Candido, nascem de uma análise das compenetrações e interdependências existentes entre o sertão e os homens que o habitam, que levam o crítico, a exemplo da definição "O Sertão é o Mundo", a dizer que "O Sertão é o jagunço". É a conclusão desse processo analítico, que Antonio Candido teoriza o célebre "princípio geral de reversibilidade". princípio, pois, que explicaria a coexistência e o funcionamento de todas as ambigüidades que caracterizam o grande romance rosiano:

Estas considerações sobre o poder reciproco da terra e do homem nos levam à idéia de que há em Grande sertão: veredas uma espécie de grande principio geral de reversibilidade, dando-lhe um caráter fluido e uma misteriosa eficácia. A ela se prendem as diversas ambigüidades que revistamos, e as que revistaremos, daqui por diante. Ambigüidade da geografia [...]; dos tipos sociais $[\ldots]$; afetiva [...]; metafísica [...]. Estes diversos planos da ambigüidade compõem um deslizamento entre os pólos. uma fusão de contrários, uma dialética extremamente viva, - que nos suspende entre o ser e o não ser para sugerir formas mais ricas de integração do ser [...].

Assim, vemos misturarem-se em todos os niveis o real e o irreal, o aparente e o oculto, o dado e o suposto. ${ }^{7}$

Portanto, a atuação desse princípio, originando a mistura dos contrários e contribuindo para o aplanamento de qualquer inconciliabilidade aflorante, determina, com as palavras de Antonio Candido, "a coerência do livro [...], fundindo o homem e a terra e manifestando o caráter uno, total, do Sertão-enquanto-Mundo". . É, então, graças a esse "princípio geral de reversibilidade", que é possivel a transcendência, resumida na fórmula - verdadeira pedra angular da crítica rosiana -, "O Sertão é o Mundo".

\section{II}

Já dissemos que a teorização dos citados conceitos candidianos influenciou sensivelmente uma maneira de interpretar a obra rosiana por parte da critica. Os conceitos "o Sertão é o Mundo" e

Ibidem, p. 305.

8 Ibidem, p. 305-306. 
o "princípio geral de reversibilidade", de fato, tornaram-se objeto de sucessivas discussões. cujo fim era o de completar, quando não modificar, o valor interpretativo e significativo dos mesmos. É o que se passa, por exemplo, com os três ensaios objeto de estudo da presente seção de trabalho, a saber: "Grande sertão e Dr. Faustus" (1960), de Roberto Schwarz; "O mundo misturado. Romance e experiência em Guimarães Rosa" (1994), de Davi Arrigucci Jr.; "O romance de Rosa. Temas do Grande sertĩo e do Brasil" (1997), de José Antônio Pasta Júnior.

A escolha desses três ensaios foi motivada por considerações tanto cronológicas - os três se inserem num percurso crítico seqüencial, fortemente intertextual, capaz de mostrar o caráter sempre atual das teorizações candidianas -, como teoréticas - os três chegam a conclusões interpretativas distintas, às vezes discordantes e, por isso mesmo, merecedoras de interesse. Além disso, a maneira de os ensaios enfrentarem os conceitos candidianos parte, mais ou menos, de uma mesma premissa questionadora: considerado que em Grande sertão: veredas "o Sertão é o Mundo", como se dá a passagem de um ao outro? E, em última instância: existe um qualquer tipo de mediação nisto? Parece, de fato, que em seu ensaio. Antonio Candido não soube ilustrar completamente ou devidamente esse ponto crucial da sua fórmula teorética, embora ele considerasse o caráter peculiar da invenção rosiana - transformadora da realidade em símbolo através de um processo de reversibilidade dos elementos em jogo -, a causa primeira da transcendência implícita em "O Sertão é o Mundo". Esta, pois, é a questão sobre um dos pontos mais debatidos da teorização candidiana, que os três autores mencionados se dispõem a solucionar $\mathrm{em}$ seus respectivos ensaios.

\section{Roberto Schwarz e a ausência da História}

Em "Grande sertão e Dr. Faustus" (escrito três anos depois da formulação dos conceitos candidianos e posteriormente inserido no livro A sereia e o desconfiado, 1965), Roberto Schwarz efetua um estudo comparativo entre Grande sertaio: veredas c o Dr. Fanstus (1947) de Thomas Mann. A idéia do cotejo dos dois romances, conforme Schwarz afirma na primeira nota de seu trabalho, deve-se "à 
generosidade intelectual de Jacó Guinsburg"." embora uma primeira sugestão, nesse sentido - isto é, na maneira de interpretar o romance rosiano à luz do drama fäustico e de uma simbologia relativa ao demoniaco -, já apareça in muce no ensaio de Antonio Candido. ${ }^{10}$

Na primeira parte de seu ensaio, Roberto Schwarz se preocupa em fazer um levantamento das semelhanças - da estrutura narrativa. das personagens protagonistas (Riobaldo em Grande sertão: veredas; Adrian Leverkuehn em Dr: Faustus) e de conteúdo - existentes entre os dois romances em questão: ambos são considerados dramas fáusticos; a narração dos acontecimentos é feita de memória, a posteriori, por uma personagem narradora: faz-se uso de um mito de derivação medieval (o Fausto) para a organização das estruturas narrativas; o diabólico é utilizado como produto cultural e não como força sobrenatural ou extra-humana; etc.

$\mathrm{Na}$ segunda parte, porém (essa pertinente para o nosso traço distintivo fundamental surgido do cotejo dos dois romances, uma primeira conclusão:

Enquanto a relação de Riobaldo com seu meio é genérica, apontando para o universal, no caso de Leverkuehn temos a interposição de uma camada histórica. Em Grande sertão faz-se passagem direta do particular à consideração mais geral [...]: em Dr. Faustus o itinerário para a universalidade passa pela dimensão de uma camada a mais, o destino da Alemanha. ${ }^{11}$

Roberto Schwarz, portanto, retomando a fómula candidiana de "O Sertão é o Mundo", chega à conclusão de que a passagem "do particular" (o contexto regional de Minas) "à consideração mais geral", isto é, aos valores universais nele expressos, é direta, imediata, ou scja, dá-se sem nenhum tipo de mediação - ao passo que em $D r$. Fousstus, a passagem do particular (a situação pessoal vivida por

"Roberto Schwarz, Grande sertão e Dr. Faustus. In: Eduardo F. Coutinho (org.), Guimaries Rosa, op. cit., p. 382.

I." - $|\ldots|$ Se encararmos a individualidade de Riobaldo, a sua condição smgular de homem, o demonio volta a simbolizar, como para Fausto ou Peter Schlemilh, a tentação e o mal." (Antonio Candido, O homem dos aressos, op. cit., p. 306).

11 Roberto Schwarz. Grande sertão e Dr. Faustus, op. cit. p. 388. 
Adrian Leverkuehn) aos valores universais, efetiva-se por intermédio de "uma camada a mais", uma camada propriamente históriconacional, a das vicissitudes da nação alemã durante os acontecimentos da Primeira e Segunda Guerra Mundial.

É mesmo essa presumida falta de "camada histórica" de Grande sertão: veredas que explicaria a transcendência imediata do Sertão em Mundo. É na falta quase absoluta da História, pois, que Roberto Schwarz avista um dado importante para a interpretação e completamento teorético do conceito candidiano, ao qual, de resto, reconhece ainda a importância da valorização da capacidade interventora e transformadora da criação artística rosiana:

Em Grande sertão a História quase não tem lugar [...]. Enquanto em Dr. Faustus a trama, no seu caminho para os valores universais, passa detidamente pelo destino alemão, em Guimarães Rosa a passagem da região para o destino humano, tomado em sentido mais geral possivel, é imediata. O sertão é o mundo, mostra Antônio Cândido [...]; o que se passa no primeiro é elaboração artistica das virtualidades do segundo. ${ }^{12}$

Mas o que Roberto Schwarz, à diferença de Antonio Candido, não reconhece, ou reconhece muito pouco, é a importância da incidência que a realidade empírica reveste no romance rosiano; realidade, como todos sabem, que Guimarães Rosa observou e introjetou após inúmeras viagens e pesquisas empreendidas pelo sertão mineiro. Com efeito, como afirma Roberto Schwarz, "Esta ligação direta [do sertão e do mundo] desobriga o autor de qualquer realismo, pois o compromisso assumido pouco se prende à realidade empírica". 13 Parece-nos que essa definição radicaliza, de fato, a posição interpretativa de Antonio Candido, que em seu ensaio, embora destacasse o poder plasmador da invenção sobre a mera descrição ou representação realística do sertão, ao mesmo tempo mostrava-se também mais propenso a reconhecer "na realidade tenazmente observada", o ponto de partida, a plataforma sobre a qual Guimarães Rosa criou a sua obra-mestra, e da qual ele não podia decerto prescindir.

As considerações finais do ensaio schwarziano chamam em causa, mais uma vez, as conceituações do Antonio Candido de "O

\footnotetext{
12 Ibidem, p. 389 (grifo do autor).

13 Ibidem.
} 
homem dos avessos", parafraseando-as e visando corroborá-las. principalmente nos aspectos tocantes à mistura dos opostos e à coexistência do real com o fantástico-simbólico. Considerações, além disso, nas quais ecoa claramente o "princípio geral de reversibilidade":

É ainda Antônio Cândido que mostra como são concebidos homem e paisagem, mesclas da realidade e simbolo, constituindo para além do mapa, da lingua e dos habitantes mineiros um regionalismo cuja referência é o globo. No coração mesmo da linguagem, tornada fluida e refeita maior, o escritor realiza esse seu constante itinerário: da realidade para o fantástico, do minimo para o imenso, do chulo para o simbolo cósmico. ${ }^{14}$

\section{Davi Arigucci Jr. e a valorização do processo histórico}

No ensaio "O mundo misturado. Romance e experiência em Guimarães Rosa” (1994), Davi Arrigucci Jr. se preocupa em detectar e analisar o "mundo misturado" de Grande sertão: veredas, projeção artístico-literária da essência misturada, em vários planos, da realidade brasileira. Abordagem de estudo esta que já Antonio Candido havia esboçado em "O homem dos avessos", remarcando a mistura - graças à imanencia de um princípio de reversibilidade - dos opostos e das ambigüidades atuantes no romance rosiano. Pois bem: Davi Arrigueci Jr. prossegue na enucleação desse aspecto da obra, detendo-se na análise da mistura ocorrente em diversos niveis: lingüístico; na caracterização das personagens; e, principalmente, narrativo, isto é. concernente aos gêneros literários.

Duas das conclusões mais importantes a que Davi Arrigucci Jr. chega em seu ensaio, dizem respeito a dois aspectos interessantes de Grande sertão: veredas. A primeira é que na representação do sertão rosiano é possivel ver a presença de um processo histórico de formação sociocultural brasileira - e para tanto o crítico se serve do exemplo do episódio do encontro do bando de Zé Bebelo com os catrumanos, ${ }^{15}$ gente que habita os "fundos fundos" do sertão mineiro em total atraso e arcaísmo, condição que efetivamente faz pensar num tempo pretérito da história nacional. À segunda conclusão em questão interessa mais o

\footnotetext{
14 Ibidem.

Davi Arrigucci Jr. O mundo misturado. Romance e experiência em Guimarães Rosa. Novos Estudos CEBRAP, n. 40, p. 16-17, nov. 1994.
} 
aspecto histórico-narrativo da obra; ela mostra a presença conjunta e "como se dá a sutura entre as formas que vêm da tradição dos narradores anônimos da épica oral sertaneja (presente desde sempre na literatura brasileira) e o nascimento de uma forma da sociedade urbana moderna - o romance - que nasce em pleno interior do Brasil". "."

A presença, no sertão rosiano, dessas duas temporalidades. uma sociocultural e outra mais propriamente sócio-literária, induziram Davi Arrigucci Jr. a revisitar o conceito candidiano de "O Sertão é o Mundo", e, por conseguinte, a revisar a noção de falta de História do ensaio schwarziano. Motivo principal dessa retomada crítica parece ser sempre o mesmo: compreender como efetivamente se dá a passagem do Sertão ao Mundo:

Embora o sertão não se enquadre claramente na História - sabemos que a história contada se passa provavelmente na segunda década deste século, em função de uma referência à Coluna Prestes e várias referências a alguns jagunços históricos e fatos realmente acontecidos -. o sertão está referido ao processo histórico (e ao mundo urbano). Da região se passa diretamente ao mundo, mas o mundo está também introjetado no sertão. Embora as balizas propriamente históricas sejam poucas no relato, a temporalidade histórica está presente no interior do sertão enquanto processo, como uma dimensão da matéria vertente, de que trata o relato. Até onde se pode ver com mais clareza, Rosa oculta ou dissolve as marcas da História, incorporando, no entanto, o processo.

Apesar desse procedimento, é possivel notar a significativa mistura dos niveis da realidade histórica, combinados nas profundezas do sertão, demonstrando como esse espaço tão particular se acha siderado pelos valores da cidade, que penetram nos modos de vida onde parece que reina apenas a natureza. ${ }^{17}$

Para Davi Arrigucci Jr., assim como a seu tempo constatamos para Roberto Schwarz, a transcendência do Sertão em Mundo acontece sem nenhuma mediação, mas $\operatorname{sim}$ de forma dircta; ${ }^{1 \times}$ situação

16. Ibidem, p. 24.

17 Ibidem, p. 16.

18 Mais adiante, na página 21 de seu ensaio, Davi Arrigucei Jr. reforça essa opinião confirmando que "A passagem do grande sertão ao vasto mundo $i$ imediata", e acrescentando em nota (n. 47) ao mesmo trecho, que era o "ensaio pioneiro de Antonio Candido sobre o livro que já sugeria esse fato desde o seu titulo: 'O sertão e o mundo', concluindo pela afimação: 'O Sertão é o munk k, '.". 
que o leva a observar - retomando uma definição usada por Harry Levin em um estudo sobre James Joyce - que o regionalismo expresso por Guimarães Rosa se poderia considerar um "regionalismo cósmico". 19 Mesmo reconhecendo, como Roberto Schwarz, a falta quase absoluta da História - cujas marcas na verdade foram em parte ocultadas ou dissolvidas pelo escritor mineiro -, Davi Arrigucei Jr., no entanto, avista no romance rosiano à presença misturada e não sempre imediatamente inteligivel do processo histórico referente à realidade social e cultural, lato sensu, do sertão mineiro. Assim sendo, Davi Arrigucci Jr. chega a proporcionar uma contribuição que vai enriquecer a fórmula candidiana "O Sertão é o Mundo" de mais uma significação interpretativa: isto é: se "O Sertão é o Mundo", é outrossim lícito considerar - em virtude tanto dessa presença do processo histórico nacional e do mundo urbano (principalmente através da forma narrativa do romance de formação de matriz. burguesa), como do "principio geral de reversibilidade" que rege os mecanismos internos do romance -, que "o Mundo é o Sertão". Em Davi Arrigucci Jr., pois, a interdependência e mistura dos dois termos da förmula candidiana fazem-se completas.

\section{A teorização limite de José Antônio Pasta Júnior: "a mediação é a imediatidade"}

Dos três estudos críticos sucessivos ao ensaio "O sertão e o mundo" considerados neste trabalho, o último, o de José Antônio Pasta Júnior - cujo titulo é "O romance de Rosa. Temas do Grande scrlio e do Brasıl" (1997) -, é não só o de maior complexidade teorética, mas também o que, de uma certa forma, leva às extremas conseqüências a interpretação da fórmula "O Sertão é o Mundo".

Também para Pasta Júnior a temática do hibridismo, da mistura dos opostos, é uma questão central para o entendimento efetivo do romance rosiano. E quando se trata de enfrentar este assunto. é inevitável a referência ao legado conceptual do "princípio geral de reversibilidade", que induz o próprio critico a afirmar, entre outras coisas, que Grande sertão: veredas é um "mundo [...] de reversibilidade continua".20 Mesmo assim, Pasta Júnior demonstra ir

19) Ihidem, ver p. 21 e nota 48.

20) José Antônio Pasta Junior. O romance de Rosa. Temas do Grande sertióo e do Brasil. In: Anne-Marie Quint (org.). La l'ille: exaltation et distanciation Fitudes de littirature portugaise et brésilienne. 1997, p. 169. 
além do princípio candidiano. O que ele quer realmente detectar e formular é um outro princípio, mais ambicioso, que reja não só o anterior, mas que represente "a lógica de base do livro e responde pelo conjunto de sua estruturação formal". ${ }^{21} \mathrm{Na}$ busca e elucidação desse princípio, Pasta Júnior chega a formular outros conceitos interpretativos, cujo intento é o de proporcionar uma chave de leitura dos mecanismos básicos não só do romance rosiano, mas, analogamente, também de outras obras capitais da literatura brasileira.

Não é nossa intenção deter-nos demasiadamente nessas teorizações, o que, aliás, estaria fora do argumento deste trabalho. Contudo, para que entendamos a proposta teorética e original de Pasta Júnior acerca da retomada do conceito candidiano "O Sertão é o Mundo", e da relativa questão sobre como se efetiva a passagem de um no outro - toda concentrada, significativamente, no fecho do ensaio -, será necessário mostrar sinteticamente as passagens e as conclusões lógico-analíticas que as precedem.

Pois bem: o procedimento teorético de Pasta Júnior parte de uma premissa histórica de cunho sócioeconômico: a presença conjunta, na história brasileira, de um regime escravista e de outro capitalista teria contribuído para o aparecimento de um hibridismo e de uma contraditoriedade de formas e relações interpessoais e sociais, que, de reflexo, se teriam repercutido nas produções culturais e literárias nacionais. Dito em outros termos, e querendo esquematizar tudo em um plano que prevê as relações sujeito/objeto, a contradição seria determinada pelo fato que, enquanto no regime escravista o sujeito é igual ao objeto (com conseguinte negação da alteridade e da autonomia do outro), no regime capitalista o sujeito é diferente do objeto (com conseguinte reconhecimento dessa alteridade e autonomia). ${ }^{22}$ Ora, é mesmo "a vigência simultânea de dois regimes da relação sujeito-objeto um que supõe a distinção entre sujeito e objeto ou, se se quiser, o mesmo e o outro, e um segundo que supõe a indistinção de ambos", que constitui a "matriz de todas as misturas", 23 inclusive das que caracterizam Grancle sertão: veredas. É este o "princípio de hibridização", que Pasta Júnior, conforme dissemos anteriormente, considera o verdadeiro "princípio organizador" do romance rosiano e que, por essa sua qualidade,

\footnotetext{
21 Ibidem, p. 161.

22 Ibidem, p. 166-167.

23 Ibidem, p. 160.
} 
explicaria, in totum, a origem e o funcionamento do mesmo "princípio geral de reversibilidade" candidiano.

O "princípio de hibridização" acima referido, porém, não tem uma valência estável; ao contrário: como a contradição interna que o constitui é insolúvel, ele acarretará um processo de mutações contínuas (um "movimento pendular contínuo"), que, por isso mesmo, será incapaz de determinar qualquer tipo de superação ou sintese desse mesmo processo. É por isso que, paradoxalmente, este estado de coisas gerará uma dupla situação que será "de movência obrigatória e fixidez inamovivel, de metamorfose contínua e pura repetição", ${ }^{24}$ tudo agindo simultaneamente e tudo governado pelo mesmo princípio.

O interesse de Pasta Júnior, a esse ponto, é saber "o modo pelo qual a simultânea distinção e indistinção de sujeito e objeto, do mesmo e do outro, impõe a um tempo a mutação contínua e a repetição do mesmo, o movimento e a parada, a metamorfose e a imutabilidade" - situação, por exemplo, que é claramente verificável na personagem de Riobaldo. Isto é possivel só se se afirma, como diz o crítico, que "o mesmo é o outro", ou, é equivalente, que "o ser é o não-ser". 25 A passagem do mesmo no outro, por sua vez, é possível só através da supressão do mesmo, que, tornando-se o outro, suprime-o para se tornar novamente o mesmo; tudo segundo um regime transformacional que Pasta Júnior define como "o da formação como supressão ou, se se quiser, o da má infinidade, em que a mutação incessante das formas é um movimento sem resultado, fluxo contínuo e mutante, porém baldado". 26 A passagem do mesmo no outro.

24 Ibidem, p. 161.

25 lbidem, p. 162. Embora a conceituação de Pasta Júnior demonstre possuir uma originalidade e complexidade próprias, estimamos ter sido Antonio Candido quem primeiro sugeriu um estudo do hibridismo rosiano nos termos avançados por Pasta Júnior: "Estes diversos planos da ambigüidade compõem um deslizamento entre os pólos, uma fusão de contrários, uma dialética extremamente viva, - que nos suspende entre o ser e o não-ser para sugerir formas mais ricas de integraça do ser." Cf. Antonio Candido, O homem dos avessos, op. cit., p.305 (grifo nosso).

20. Ibidem, p. 163. É, porém, nossa convicçào crer que o "regime da formação como supressão" atue mais segundo um processo propriamente sincrético em que, por exemplo, dados dois elementos A e B (suponhamos o ser e o năo-ser), os dois se fundem (e portanto suprimem a sua essência originária, como aliás acontece no exemplo de Pasta Júnior) a constituirem um novo 
imprescindivel para que o ser seja o não-ser, é, pois. " mediada apenas pela destruição, pois se o mesmo suprime o outro apossando-se dele, por seu turno este o aniquila, ocupando-lhe o lugar". ${ }^{27}$ Tudo, portanto, procede segundo uma dinâmica definida pelo próprio crítico de "luta de morte", capaz de acionar "o pêndulo da má infinidade, em sua oscilação interminável entre pólos opostos". 28

A série de teorizações apresentadas por Pasta Júnior finda no esclarecimento de outro conceito, último mecanismo do "princípio de hibridização" (ou, se se quiser, da passagem do mesmo no outro) a ser explicado, que completaria a ilustração dos funcionamentos inerentes a Grande sertão: veredas. Esse conceito, que o crítico chama de "regime do limite", mostra como durante a fase de passagem do mesmo no outro existe um ponto infinitesimal (o limite) em que imediatamente se dá esse momento transformacional. "." "Regime do limite" este, da maior pertinência para o nosso estudo, já que é por meio dele que Pasta Júnior proporcionará a sua pessoal interpretação de "O Sertão é o Mundo", limitadamente à compreensão da maneira pela qual se dá a transição de um para o outro. É, ademais, muito significativo que essa contribuição de Pasta Júnior represente o remate do ensaio, pois, conforme já aconteceu com o "Grande sertão e Dr. Faustus" de Roberto Schwarz, para a legitimação de quaisquer novas teorizações sobre Grande sertão: veredas, parece como que indispensável o confronto interpretativo com os princípios candidianos, verdadeiras pedras de toque da crítica rosiana. É assim. pois, que sobre o assunto se exprime Pasta Júnior, retomando, nisto, uma importante afirmação que o próprio Guimarães Rosa deixou numa entrevista (janeiro de 1965) ao crítico alemão Günter Lorenz:

"Riobaldo é apenas o Brasil", disse Rosa em célebre entrevista - afirmação que, por si só, relança a polêmica quanto a se saber se, enfim, em Rosa, o salto do sertão para o mundo é imediato ou se, ao contrário, ele passa por

elemento C (um novo ser). que. por isso mesmo, é o ser e o não-ser e ao mesmo tempo não o é. Se a nossa consideração for correta, é também licito afirmar que esse processo transformacional nào é absolutamente um movimento sem resultado ou baldado, mas sim leva sempre a uma conclusão que é diferente dos elementos formativos de partida, já que o ser inicial não é mais perfeitamente igual ao ser final.

Ibidem, p. 164.

Ibidem.

26) Ibidem, p. 168. 
uma mediação essencial, que è o Brasil. Observando o regime do limite que vige no livro, talvez vejamos que ambas as posições estão certas e erradas ao mesmo tempo. É inerente à formação supressiva, própria ao regime do limite, que ela ponha a mediação no e pelo mesmo movimento em que a subtrai. Assim, é certo que o Grande sertão passa pela mediação do Brasil, mas é igualmente certo que, nele, a mediação é a imediatidade. ${ }^{30}$

Expresso com outras palavras, que talvez ajudem a esclarecer mclhor o trecho que acabamos de citar, poderiamos dizer que: a passagem do Sertão (o ser) no Mundo (o não-ser) se dá, conforme vimos, por meio da "formação supressiva", cujo momento decisivo é o "reggime do limite". A passagem do Sertão no Mundo é pois mediada pelo limite - de forma pressuposta, o Brasil - que, porque limite, é por isso mesmo momento infinitesimal. Disto pode-se inferir que a passiagem efetiva-se, sim, pela mediação do limite-Brasil, mas que scudo esse limite, segundo a teorização de Pasta Júnior, instantâneo, essa mediação é imediata. Daí a lógica conclusão do crítico dizer que “a médiação é a imediatidade".

Com Pasta Júnior pois, "O Sertão é o Mundo" adquire mais uma importante - e certamente não derradeira - contribuição interpretativa, talvez a mais articulada e dupla, como duplo é, aliás, o mundo narrado em Grande sertão: veredas.

\section{REIER̂E.NCIAS BIBLIOGRÁFICAS}

ARRIGIC'CI JUNIOR, Davi. O mundo misturado. Romance e experiencia em Gumarães Rosa. Novos Estudos CEBRAP, n. 40, nov. 1004 .

( INI)II)O. Antonio. O homem dos avessos. In: COUTINHO. I:duardo I: (org.). Guimarães Rosa. 2. ed. Rio de Janeiro: Civilização Brasileira, 1991. (Col. Fortuna Crítica, 6)

(') IINHO, Eduardo F. (org.). Guimaräes Rosa. 2. ed. Rio de lanciro: (ivilização Brasileira, 1991. (Col. Fortuna Crítica, 6)

Ibidem, p. 170 . 
PASTA JÚNIOR, José Antônio. O romance de Rosa. Temas do Grande sertão e do Brasil. In: QUINT, Anne-Marie (org.). La Ville: exaltation et distanciation - Études de littérature portugaise et brésilienne. Paris: Presses de La Sorbonne Nouvelle, Centre de Recherche sur les Pays Lusophones-Crepal, Cahier n. 4, outono de 1997.

QUINT, Anne-Marie (org.). La Ville: exaltation et distanciation Études de littérature portugaise et brésilienne. Paris: Presses de La Sorbonne Nouvelle, Centre de Recherche sur les Pays LusophonesCrepal, Cahier n. 4, outono de 1997.

SCHWARZ, Roberto. Grande sertão e Dr. Faustus. In: COUTINHO, Eduardo F. (org.). Guimarìes Rosa. 2. ed. Rio de Janeiro, Civilização Brasileira, 1991. (Col. Fortuna Crítica, 6) 